\title{
Focused ultrasound development and clinical adoption: 2013 update on the growth of the field
}

Dasha Tyshlek', Jean-Francois Aubry ${ }^{2,3}$, Gail ter Haar ${ }^{4}$, Arik Hananel ${ }^{1,2^{*}}$, Jessica Foley ${ }^{1}$, Matthew Eames ${ }^{1}$, Neal Kassell ${ }^{1,5}$ and Heather Huff Simonin ${ }^{1}$

\begin{abstract}
The field of therapeutic focused ultrasound, which first emerged in the 1940s, has seen significant growth, particularly over the past decade. The eventual widespread clinical adoption of this non-invasive therapeutic modality require continued progress, in a multitude of activities including technical, pre-clinical, and clinical research, regulatory approval and reimbursement, manufacturer growth, and other commercial and public sector investments into the field, all within a multi-stakeholder environment. We present here a snapshot of the field of focused ultrasound and describe how it has progressed over the past several decades. It is assessed using metrics which include quantity and breadth of academic work (presentations, publications), funding trends, manufacturer presence in the field, number of treated patients, number of indications reaching first-in-human status, and quantity and breadth of clinical indications.
\end{abstract}

\section{Content}

Introduction

The first publication to demonstrate focused ultrasound's potential therapeutic use appeared in 1942 [1]. Over the following decade, focused ultrasound was investigated as a potential treatment for neurofunctional disorders, specifically Parkinson's disease [2,3]. At this initial stage, the transmission of acoustic energy into the brain was an invasive procedure because of the reflection, absorption, and diffraction produced by the skull. Real-time image guidance was not available at the time. An offline X-ray was therefore used to guide the beams from the singleelement therapeutic ultrasound transducers which were mounted on a stereotactic frame.

The Food and Drug Administration (FDA) first approved a focused ultrasound (FUS) device in 1988 [4,5]. This device provided non-invasive treatment of glaucoma under ultrasound and optical imaging guidance [6-8].

In the 1950s, Vallancien et al. reported clinical results with a new system that employed ultrasound imaging for guidance and a thermocouple for thermal measurements.

\footnotetext{
* Correspondence: ahananel@fusfoundation.org

${ }^{1}$ Focused Ultrasound Foundation, Charlottesville, VA 22903, USA

2Department of Radiation Oncology, University of Virginia, Charlottesville, VA 22901, USA

Full list of author information is available at the end of the article
}

This system was used to treat patients with bladder cancer [9] and prostatic, liver, and renal tumors [10]. This led in 2000 to the first Conformité Européenne (CE) approval for this indication.

Magnetic resonance imaging (MRI)-guided focused ultrasound devices were introduced in the early 1990s [11-14], with the first device obtaining CE approval in 2003 and FDA approval in 2004, for the treatment of symptomatic uterine fibroids.

The development of multielement transducers $[15,16]$ allowed electronic beam steering around the geometrical focus $[17,18]$ and the production of multiple simultaneous foci [19]. Electronic beam steering can be used either to treat large areas without moving the therapeutic probe [20] or to perform motion compensation [21]. The phase of the signal at each element can also be adjusted to provide focusing through aberrating structures such as the skull [22-27] or the ribs [28-32].

To date, a significant amount of work has been performed using various ultrasound (US)-guided and MRIguided systems for the treatment of symptomatic uterine fibroids [33,34]; brain tumors [35-37]; painful bone metastases [38,39]; prostatic [40-42], pancreatic [43], and breast [44] cancer; and abdominal tumors [45-47]. 
To date, more than 80,000 patients have been treated globally using a variety of ultrasound-guided and MRI-guided therapeutic high-intensity focused ultrasound devices.

\section{Purpose}

In order to evaluate the growth of the field of focused ultrasound, and to shine a spotlight on its current level of development and clinical adoption, two primary areas have been assessed, namely historical progress in financial support and general awareness of focused ultrasound, and the health impacts of the field.

The financial support and general awareness of focused ultrasound can be assessed by tracking the amount of research funding provided to focused ultrasound projects, the number of publications in peerreviewed journals, and general awareness metrics such as visits to specific focused ultrasound websites, including its Wikipedia page.

The impact of focused ultrasound on the health of the global community can be gleaned through examination of the number of clinical indications reaching first-in-human stage and of how many patients have been treated.

\section{Methods}

For this evaluation, several metrics and data sources were used including the annual number of publications (Medline) and citations (Thompson Reuters Web of Science); the number of abstracts presented in meetings dedicated to focused ultrasound (the annual meeting of the International Society of Therapeutic Ultrasound (ISTU-founded in 2001), the biennial meeting organized by the Focused Ultrasound Foundation (FUSF-founded in 2006), and the European Focused Ultrasound Working Group (EFUS-founded in 2011)); the clinical indications that have reached the level of human feasibility trials (obtained from literature review and communications with relevant researchers); the number of annual treatments administered (from manufacturers' reports); manufacturer growth within the field; and the amount of National Institutes of Health (NIH) funding allocated to focused ultrasound research. In addition, the number of hits on the FUS Foundation website and FUS Wikipedia page were used as indicators for general awareness of and interest in the field. This data was used to evaluate the historical progress and current status of FUS as a treatment modality for a variety of clinical indications.

The annual number of publications was obtained using the Medline trends online tool, with the search term 'focused ultrasound' which is inclusive for most other terms used in this field. The Thomson Reuters Web of Science was used to assess the number of citations per year, with the same search criterion.

Organizers of focused ultrasound-specific scientific meetings were contacted in order to assess the number of abstracts presented at these meetings. Where these organizers could not be reached, the number of publications listed in the Proceedings for these conferences was used.

Manufacturer count and type were obtained by requesting information from industry executives, online research, and information collected through focused ultrasound symposia registration and sponsorship data. Only manufacturers developing an image-guided, non-invasive device using focused ultrasound for therapy or pre-clinical research, including systems solely for animal research, were included in these metrics.

The number of patients treated was acquired for each clinical indication by contacting the relevant device manufacturers. To identify the time point at which each clinical indication reached a feasibility clinical trial, the authors surveyed researchers in the relevant clinical field, reviewed articles, and conducted specific literature searches.

$\mathrm{NIH}$ funding allocation to focused ultrasound research was obtained using the NIH RePorter database. The terms 'high intensity focused ultrasound,' 'focused ultrasound therapy,' 'ablation,' 'drug delivery,' and 'HIFU' were searched for separately, but the data was aggregated and duplicates were eliminated. Search results were further refined based on the relevance of the listed projects. Data were analyzed and presented by year, total HIFU annual funding, and funding as a percent of the total NIH budget. Total annual NIH research spending was extracted from NIH annual reports. In this work we present only NIH funding and not funding from sources in Europe and Asia because these data were not publicly available in a single location. We assume the NIH funding could be considered as a surrogate for government funding worldwide.

The visits to the FUS Foundation website were analyzed using Listrack and Google analytics. The number of Wikipedia page views was collected using stats.grok.se with the key word 'high-intensity focused ultrasound.' These general awareness metrics data were analyzed and are presented by month or quarter, with significant events highlighted on the timeline.

The data collected and the search terms apply to therapeutic focused ultrasound, with the majority on it being for high-intensity focused ultrasound, and thus distinct from non-focused therapeutic ultrasound that is used for physiotherapy or other indications.

\section{Results}

As shown in Figures 1 and 2, the absolute number of publications and citations has been increasing since the beginning of the 1990s as has the ratio of publications on focused ultrasound to the overall number of publications in Medline. 


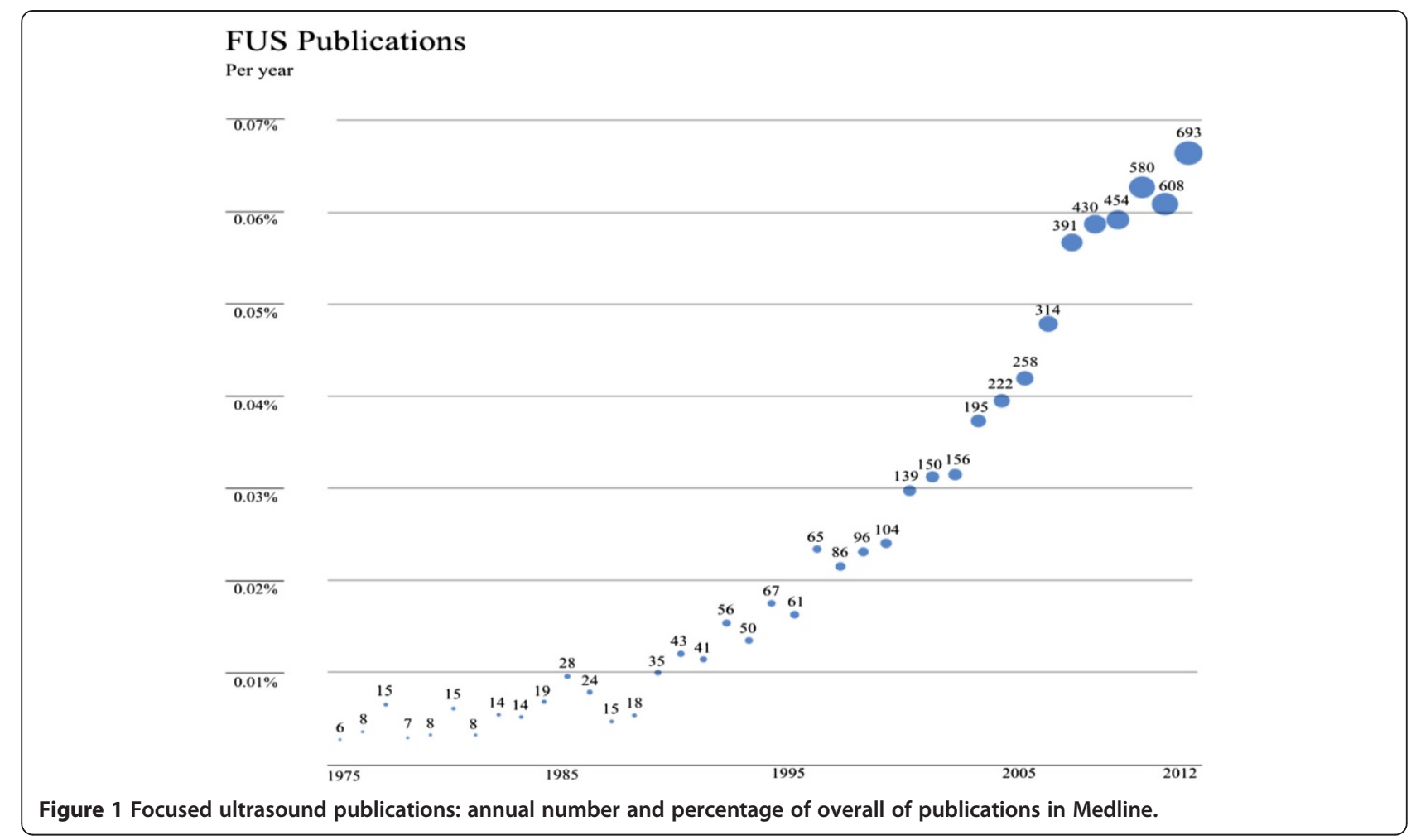

Figure 3 indicates an increase in the number of abstracts presented in FUS centric meetings. A similar trend of growth is seen in the number of manufacturers who are developing and selling devices for both clinical and animal research using various guidance methods as is shown in Figure 4 and Table 1.

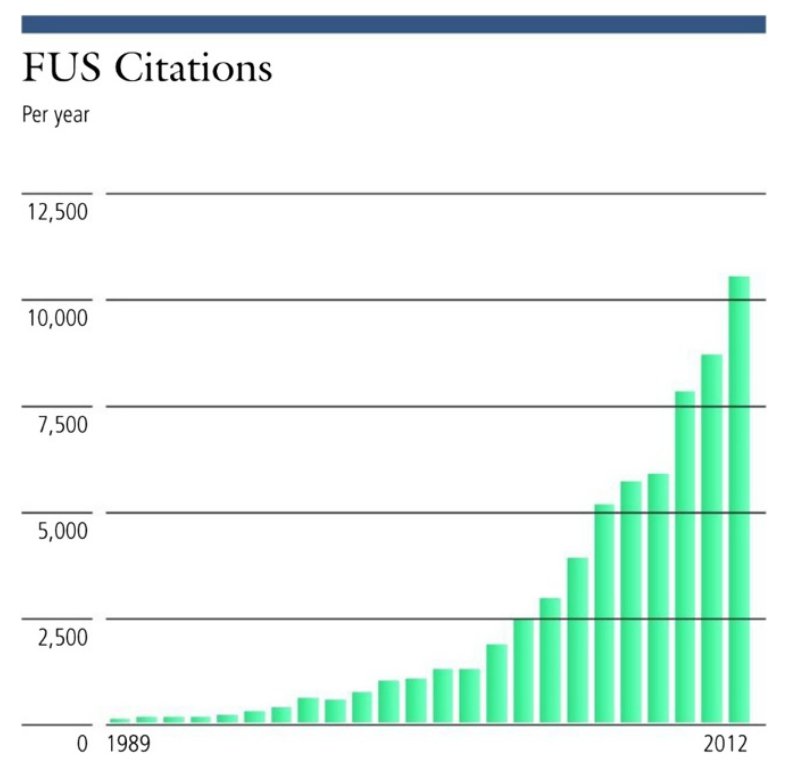

Figure 2 Annual number of citations of focused ultrasound publications.
As shown in Figure 5, more than 80,000 patients have been treated using FUS for multiple clinical indications. Many more indications are actively being researched and tested as shown in Figure 6, which demonstrates graphically the date of the first-in-human focused ultrasound treatment for each indication. Traffic to the FUS

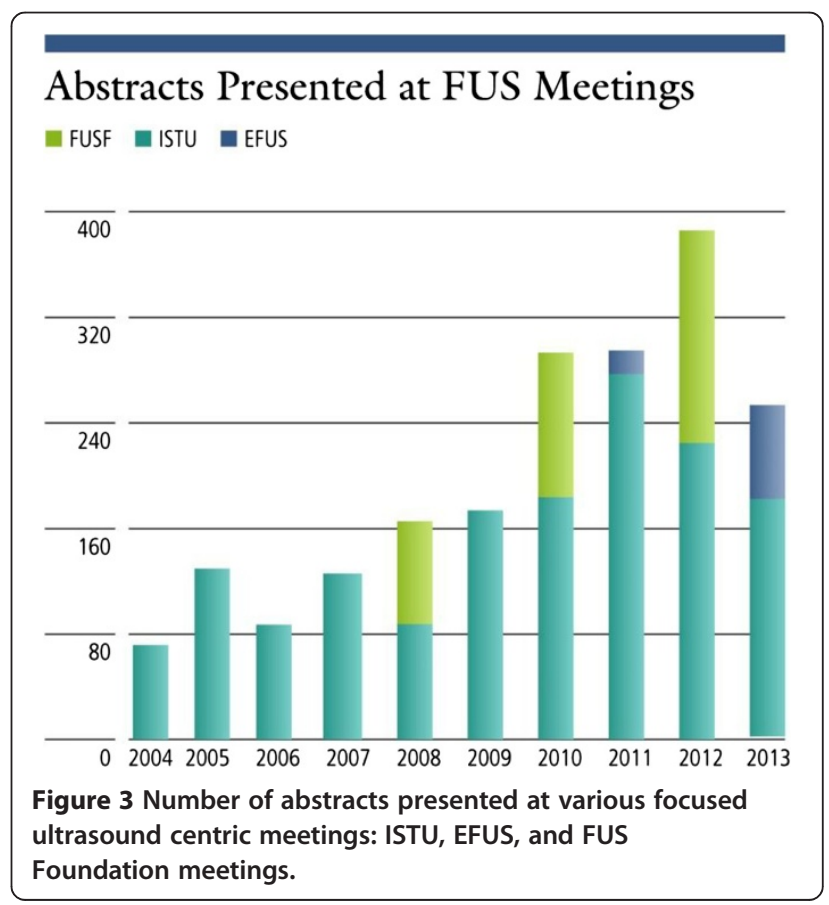




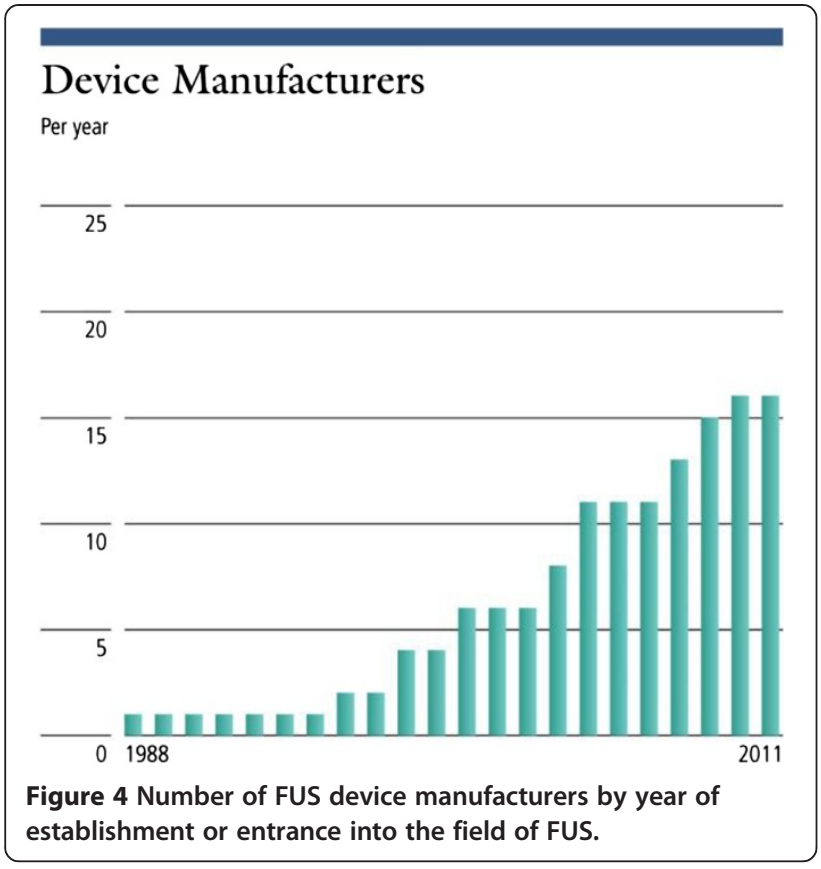

Table 1 Focused ultrasound device manufacturers

\begin{tabular}{lll}
\hline Company & Founded & $\begin{array}{l}\text { Guidance } \\
\text { and usage }\end{array}$ \\
\hline EDAP TMS & 1979 & US \\
SonaCare Medical (previously US-HIFU, & 1997 & US \\
International HIFU and Focus Surgery) & & \\
Chongqing HAIFU & 1999 & Both \\
China Medical & 1999 & US \\
Insightec & 1999 & MR \\
Image Guided Therapy & 2001 & MR-animals \\
Shanghai A\&S & 2001 & Both \\
Mirabilis & 2004 & US \\
Theraclion & 2004 & US \\
Medsonic & 2005 & MR \\
Philips Healthcare & 2005 & MR \\
Supersonic Imagine & 2005 & Both \\
Profound & 2008 & MR \\
EyeTechCare & 2008 & Visual \\
Alpinion & 2008 & US \\
International Cardio Corporation & 2009 & US \\
Kona Medical & 2009 & US \\
Histosonic & 2009 & US \\
FUS instruments & 2009 & MR—animals \\
Acublate & 2010 & Both \\
\hline Cintia incude & & \\
\hline
\end{tabular}

Criteria include guidance method (US, MR, other) and usage (if used only for pre-clinical studies, this is marked as 'animal').

\section{Treatments by Indication}

Up to 2012

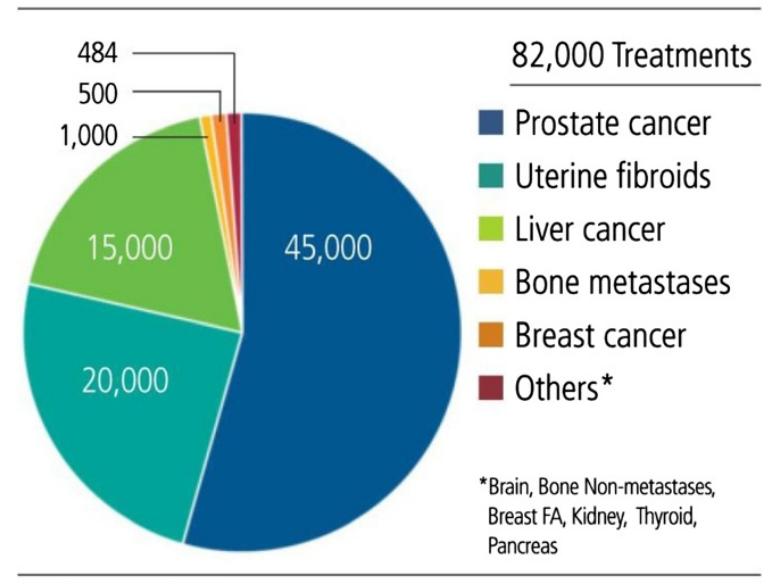

Manufacturer supplied data

Figure $\mathbf{5}$ Number of patients treated by focused ultrasound for various clinical indications.

Foundation website and to the Wikipedia article on focused ultrasound has been increasing, as can be seen in Figures 7 and 8, indicating growth in the awareness of ultrasound. On these two figures, we have also marked the date of the most recent FUS Foundation symposium and recent news coverage in $\mathrm{ABC}$, which created a local peak in the graphs. Additionally, Figure 9 shows that in the USA, policymaker awareness has also increased, as FUS has been receiving increased funding and has been growing in funding relative to total NIH finding.

\section{Discussion}

The data presented shows evidence of progress in the field of focused ultrasound. This is demonstrated by the number of clinical indications explored, which has increased from 1 to 21 since 1950, or by the increase in the amount of research as indicated by the steady increase in the number of publications. In addition, the number of abstracts at focused ultrasound events and symposia is also on the rise, indicating a higher level of activity (a similar trend may exist in non-focused ultrasound-specific symposia but was more challenging to measure). Publications and citations for focused ultrasound have also been increasing yearly and by a greater percentage than the total number of medical publications, indicating that focused ultrasound research is growing faster than medical research overall. A similar trend of growth could be seen also in the increase in funding allocated to focused ultrasound and by web traffic in sites dedicated to this topic. 


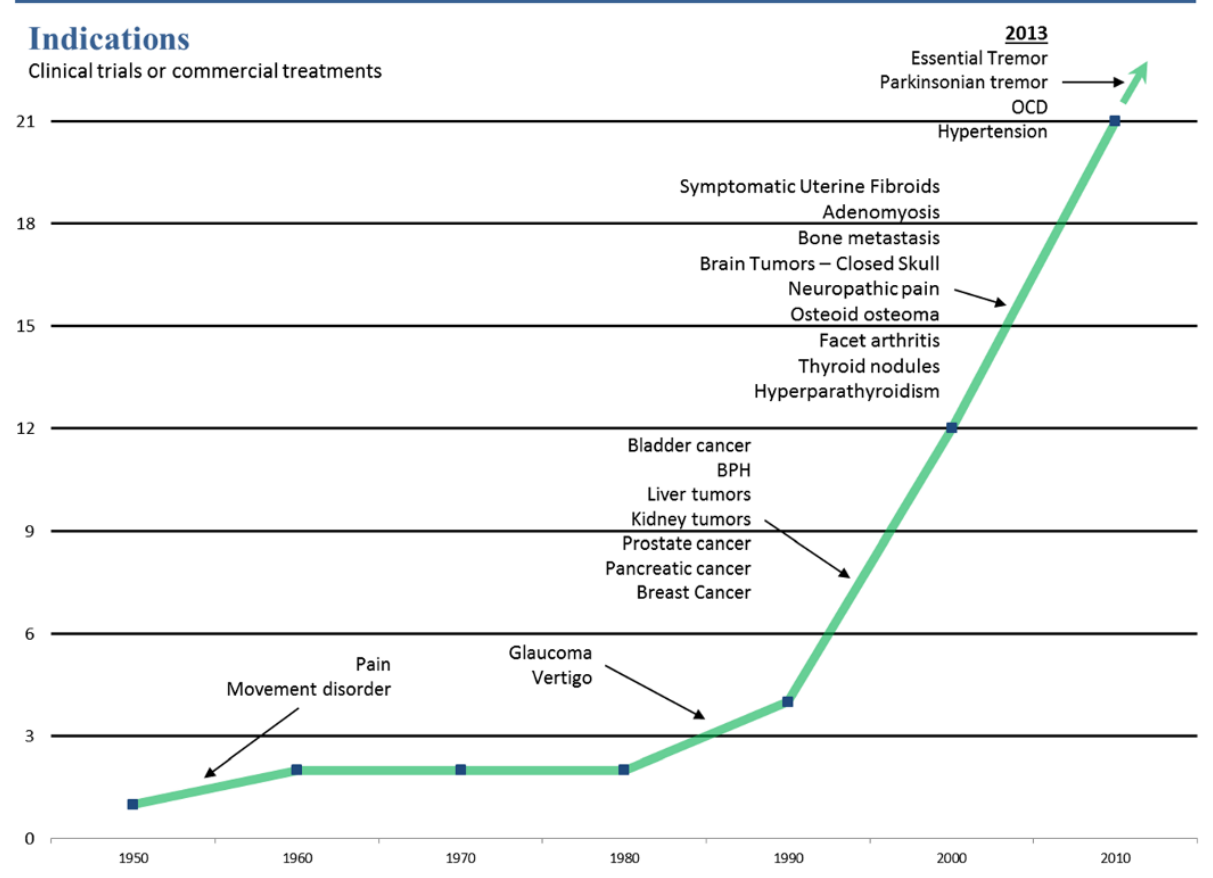

Figure 6 Number of indications reaching first-in-human over time.

This data, however, continues to pose important questions about metrics and data collection. How can the community measure progress in a field that is developing globally across many different clinical indications? Should progress be measured using translation and application or technological capability metrics? How can public awareness be measured and correlated with adoption?

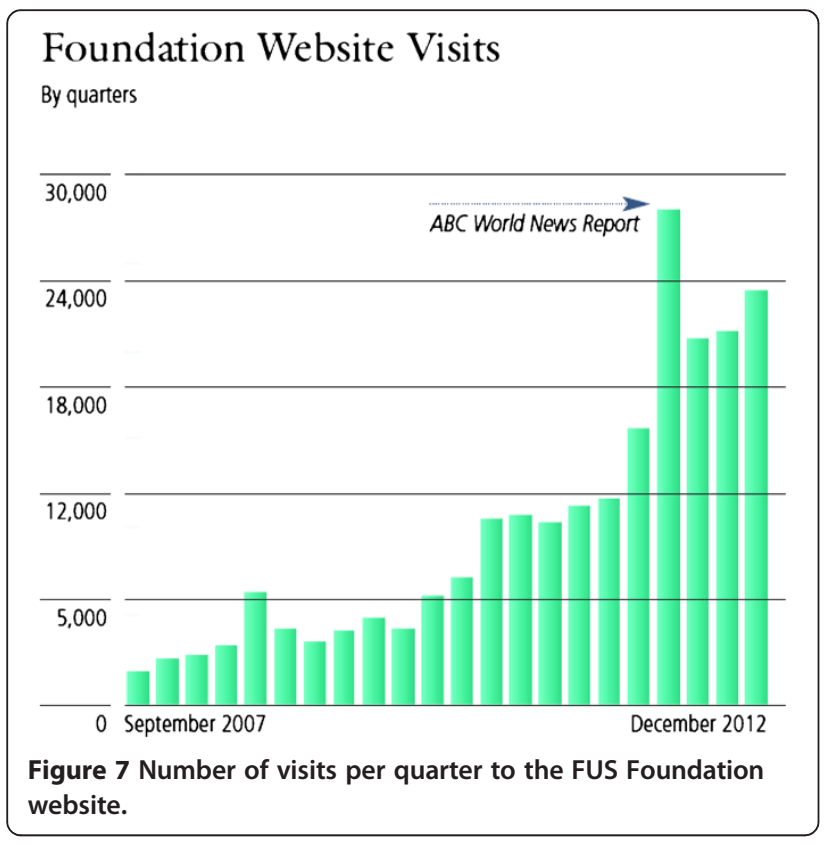

Collection of relevant data remains a challenge for the focused ultrasound community. Most funding data is publicly available only for programs in the USA. This means that some global impacts cannot, as yet, be measured or compared. Additionally, research site, manufacturer, and clinical site information is collected only for the organizations that actively participate in the focused ultrasound community and regularly submit their information on a voluntary basis. This means that it is harder to collect data

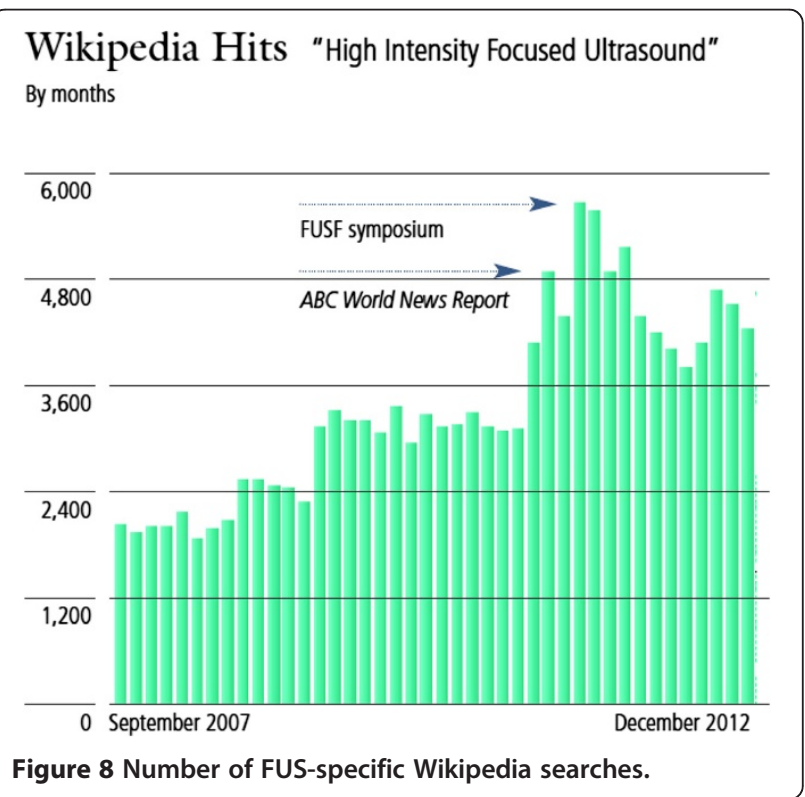




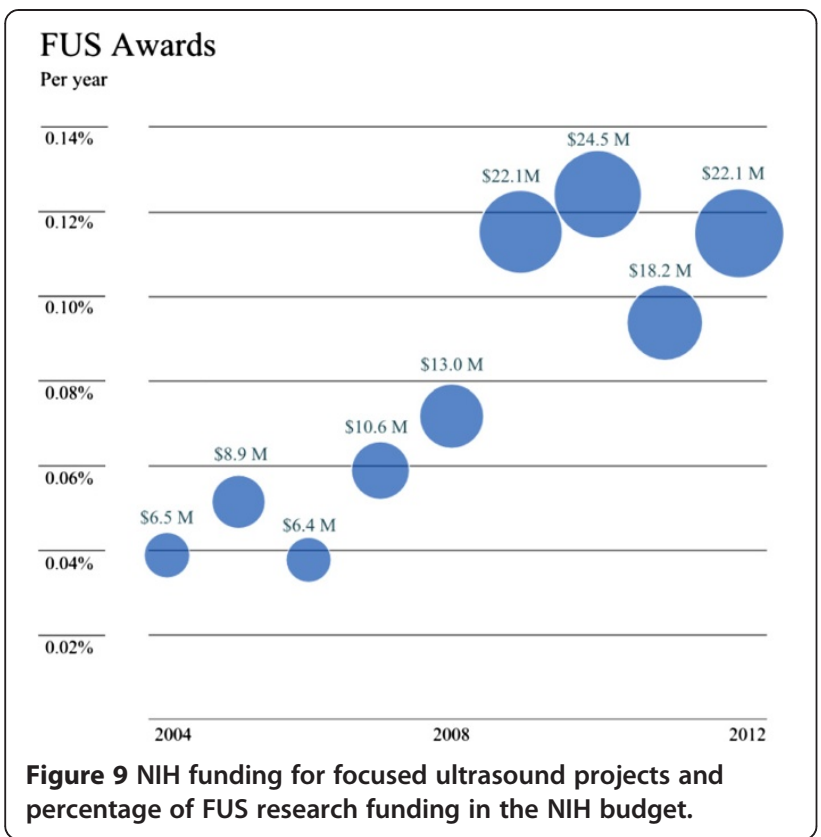

from some regions than others, skewing the geographic representations of the focused ultrasound field. The Focused Ultrasound Foundation would like to invite the community to engage with its business development team to enable better data collection and increased global awareness.

\section{Conclusion}

The field of therapeutic focused ultrasound has been steadily growing since its inception in the 1940s. The results presented here, obtained using quantitative metrics and publically accessible data sources, offer a snapshot of the progress in the development and clinical adoption of this technology. Data indicates that there is widespread progress in scientific and clinical research which may lead to increased adoption of the technologies for the benefit of patients worldwide.

This data, however, continues to pose important questions, particularly for the Focused Ultrasound Foundation. How can future growth potential be identified and our resources mobilized to maximize progress in this area? How can we overcome the barriers along the pathway from idea conception to successful patient treatment, to catalyze the process and bring this non-invasive therapy to patients faster?

The Focused Ultrasound Foundation may be the most appropriate organization to continue to track the field's progress. If so, it needs input and guidance from the focused ultrasound community to strengthen these efforts. Suggestions for further metrics relevant to the development of the field and the sharing of information in the areas currently being monitored would be welcomed.
The FUS Foundation aims to provide the most accurate information. If you have more current information, please send it to progress@fusfoundation.org.

\section{Author details \\ ${ }^{1}$ Focused Ultrasound Foundation, Charlottesville, VA 22903, USA \\ ${ }^{2}$ Department of Radiation Oncology, University of Virginia, Charlottesville, VA 22901, USA. ${ }^{3}$ Institut Langevin, CNRS UMR 7587, ESPCI ParisTech, INSERM U979, Paris 75005, France. ${ }^{4}$ Division of Radiotherapy and Imaging, The Institute of Cancer Research, Royal Marsden Hospital, Sutton, Surrey, UK. ${ }^{5}$ Department of Neurosurgery, University of Virginia, Charlottesville, VA 22901 USA.}

Received: 7 January 2014 Accepted: 24 January 2014

Published: 27 February 2014

\section{References}

1. Lynn J, Zwemer R, Chick A, Miller A. A new method for the generation and use of focused ultrasound in experimental biology. J Gen Physiol. 1942; 26:179-93.

2. Fry W, Mosberg W Jr, Barnard J, Fry F. Production of focal destructive lesions in the central nervous system with ultrasound. $J$ Neurosurg. 1954; 11:471-8.

3. Meyers R, Fry W, Fry F, Dreyer L, Schultz D, Noyes R. Early experiences with ultrasonic irradiation of the Pallidofugal and Nigral complexes in hyperkinetic and hypertonic disorders. J Neurosurg. 1958; 16:32-54.

4. Muratore R. A history of the Sonocare CST-100: the first FDA-approved HIFU device. AIP Conf Proc. 2006; 829:508-12.

5. Muratore $R$, Hananel A. The Journal of Therapeutic Ultrasound: broadening knowledge in a rapidly growing field. $J$ Therapeutic Ultrasound. 2013; 1:1-2.

6. Coleman D, Lizzi FL, Driller J, Rosado AL, Burgess SE, Torpey JH, Smith ME, Silverman RH, Yablonski ME, Chang S, Rondeau MJ. Therapeutic ultrasound in the treatment of glaucoma II. Clinical applications Opthalmology. 1985; 92:347-52.

7. Burgess S, Silverman R, Coleman D, Yablonski M, Lizzi F, Driller J, Rosado A, Dennis PH Jr. Treatment of glaucoma with high-intensity focused ultrasound. Opthalmology. 1986; 93:831-8.

8. Valtot F, Kopel J, Haut J. Treatment of glaucoma with high intensity focused ultrasound. Int Ophthalmol. 1989; 13:167-70.

9. Vallancien G, Chartier-Kastler E, Chopin D, Veillon B, Brisset JM, André-Bougaran J. Focused extracorporeal pyrotherapy: experimental results. Eur Urol. 1991; 20:211-9.

10. Vallancien G, Harouni M, Veillon B, Mombet A, Prapotnich D, Brisset J, Bougaran J. Focused extracorporeal pyrotherapy: feasibility study in man. J Endourology. 1992; 6:173-81.

11. Cline H, Schenck J, Hynynen K, Watkins R, Souza S, Jolesz F. MR-guided focused ultrasound surgery. J Comput Assist Tomogr. 1992; 16:956-65.

12. Hynynen K, Darkazanli A, Unger E, Schenck J. MRI-guided non-invasive ultrasound surgery. Med Phys. 1993; 20:107-15.

13. Ishihara Y, Calderon A, Watanabe H, Okamoto K, Suzuki Y, Kuroda K, Suzuki Y. A precise and fast temperature mapping using water proton chemical shift. Magn Reson Med. 1995; 34:814-23.

14. Hynynen K, Freund WR, Cline HE, Chung AH, Watkins RD, Vetro JP, Jolesz FA. A clinical, noninvasive, MR imaging-monitored ultrasound surgery method. Radiographics. 1996; 16:185-95.

15. Daum DR, Hynynen K. A 256-element ultrasonic phased array system for the treatment of large volumes of deep seated tissue. IEEE Trans Ultrason Ferroelectr Frea Control. 1999; 46:1254-68.

16. Ebbini ES, Cain CA. A spherical-section ultrasound phased array applicator for deep localized hyperthermia. Biomed Eng IEEE Trans. 1991; 38:634-43.

17. Pernot M, Aubry JF, Tanter M, Thomas JL, Fink M. High power transcranial beam steering for ultrasonic brain therapy. Phys Med Biol. 2003; 48:2577-89.

18. Diederich CJ, Hynynen K. The feasibility of using electrically focused ultrasound arrays to induce deep hyperthermia via body cavities. Ultrason Ferroelectr Frea Control IEEE Trans. 1991; 38:207-19.

19. Ebbini ES, Cain CA. Multiple-focus ultrasound phased-array pattern synthesis: optimal driving-signal distributions for hyperthermia. Ultrason Ferroelectr Freq Control IEEE Trans. 1989; 36:540-8.

20. Salomir R, Palussière J, Vimeux FC, de Zwart JA, Quesson B, Gauchet M, Lelong P, Pergrale J, Grenier N, Moonen CT. Local hyperthermia with 
MR-guided focused ultrasound: spiral trajectory of the focal point optimized for temperature uniformity in the target region. J Magn Reson Imaging. 2000; 12:571-83.

21. Tanter M, Pernot M, Aubry J, Montaldo G, Marquet F, Fink M. Compensating for bone interfaces and respiratory motion in high intensity focused ultrasound. Int J Hyperthermia. 2007; 23:141-51.

22. Clement GT, White J, Hynynen K. Investigation of a large-area phased array for focused ultrasound surgery through the skull. Phys Med Biol. 2000; 45:1071-83.

23. Aubry JF, Tanter M, Pernot M, Thomas JL, Fink M. Experimental demonstration of noninvasive transskull adaptive focusing based on prior computed tomography scans. J Acoust Soc Am. 2003; 113:84-93.

24. White J, Clement GT, Hynynen K. Transcranial ultrasound focus reconstruction with phase and amplitude correction. IEEE Trans Ultrason Ferroelectr Frea Control. 2005; 52:1518-22.

25. Marsac L, Chauvet D, Larrat B, Pernot M, Robert B, Fink M, Boch AL, Aubry JF, Tanter M. MR-guided adaptive focusing of therapeutic ultrasound beams in the human head. Med Phys. 2012; 39:1141.

26. Elias WJ, Khaled M, Hilliard JD, Aubry J-F, Frysinger RC, Sheehan JP, Wintermark M, Lopes MB. A magnetic resonance imaging, histological, and dose modeling comparison of focused ultrasound, radiofrequency, and Gamma Knife radiosurgery lesions in swine thalamus. J Neurosurg. 2013; 119:307-17.

27. Chauvet D, Marsac L, Pernot M, Boch A-L, Guillevin R, Salameh N, Souris L, Darrasse L, Fink M, Tanter M, Aubry JF. Targeting accuracy of transcranial magnetic resonance-guided high-intensity focused ultrasound brain therapy: a fresh cadaver model. J Neurosurg. 2013; 118:1046-52.

28. McGough RJ, Kessler M, Ebbini E, Cain C. Treatment planning for hyperthermia with ultrasound phased arrays. Ultrason Ferroelectr Freq Control IEEE Trans. 1996; 43:1074-84

29. Aubry JF, Pernot M, Marquet F, Tanter M, Fink M. Transcostal high-intensityfocused ultrasound: ex vivo adaptive focusing feasibility study. Phys Med Biol. 2008; 53:2937-51.

30. Cochard E, Prada C, Aubry J, Fink M. Ultrasonic focusing through the ribs using the DORT method. Med Phys. 2009; 36:3495-503.

31. Bobkova S, Gavrilov L, Khokhlova V, Shaw A, Hand J. Focusing of highintensity ultrasound through the rib cage using a therapeutic random phased array. Ultrasound Med Biol. 2010; 36:888-906.

32. Civale J, Clarke R, Rivens I, ter Haar G. The use of a segmented transducer for rib sparing in HIFU treatments. Ultrasound Med Biol. 2006; 32:1753-61.

33. Stewart EA, Rabinovici J, Tempany CM, Inbar $Y$, Regan L, Gostout $B$, Hesley G, Kim HS, Hengst S, Gedroyc WM. Clinical outcomes of focused ultrasound surgery for the treatment of uterine fibroids. Fertil Steril. 2006; 85:22-9

34. Rabinovici J, David M, Fukunishi H, Morita Y, Gostout BS, Stewart EA. Pregnancy outcome after magnetic resonance-guided focused ultrasound surgery (MRgFUS) for conservative treatment of uterine fibroids. Fertil Steril. 2010; 93:199-209.

35. Jeanmonod D, Werner B, Morel A, Michels L, Zadicario E, Schiff G, Martin E. Transcranial magnetic resonance imaging-guided focused ultrasound: noninvasive central lateral thalamotomy for chronic neuropathic pain Neurosurg Focus. 2012; 32:1-11.

36. Elias WJ, Huss D, Voss T, Loomba J, Khaled M, Zadicario E, Frysinger RC, Sperling SA, Wylie S, Monteith SJ, Druzgal J, Shah BB, Harrison M, Wintermark M. A pilot study of focused ultrasound thalamotomy for essential tremor. N Engl J Med. 2013; 369:640-8.

37. Lipsman N, Schwartz ML, Huang Y, Lee L, Sankar T, Chapman M, Hynynen K, Lozano AM. MR-guided focused ultrasound thalamotomy for essential tremor: a proof-of-concept study. Lancet Neurol. 2013; 12:462-8.

38. Turkevich V, Savelyeva V, Kanaev S, Dunaevsky I, Krzhivitsky P. Treatment of painful bone metastases with magnetic resonance guided focused ultrasound. Eur J Cancer. 2011; 47:227-8.

39. Liberman B, Gianfelice D, Inbar Y, Beck A, Rabin T, Shabshin N, Chander G, Hengst S, Pfeffer R, Chechick A, Hanannel A, Dogadkin O, Catane R. Pain palliation in patients with bone metastases using MR-guided focused ultrasound surgery: a multicenter study. Ann Surg Oncol. 2009; 16:140-6.

40. Chaussy $C$, Thuroff S. High-intensity focused ultrasound in the management of prostate cancer. Expert Rev Med Devices. 2010; 7:209-17.

41. Royce PL, Sothilingam S. Sonablate HIFU therapy for prostate cancer initial clinical outcomes. BJU Int. 2008; 101:11.
42. Crouzet S, Murat FJ, Pasticier G, Cassier P, Chapelon JY, Gelet A. High intensity focused ultrasound (HIFU) for prostate cancer: current clinical status, outcomes and future perspectives. Int J Hyperthermia. 2010; 26:796-803.

43. Wu F, Wang ZB, Zhu H, Chen WZ, Zou JZ, Bai J, Li KQ, Jin CB, Xie FL, Su HB. Feasibility of US-guided high-intensity focused ultrasound treatment in patients with advanced pancreatic cancer: initial experience. Radiology. 2005; 236(3):1034-40. doi:10.1148/radiol.2362041105.

44. Schmitz AC, Gianfelice D, Daniel BL, Mali WP, van den Bosch MA. Image-guided focused ultrasound ablation of breast cancer: current status, challenges, and future directions. Eur Radiol. 2008; 18:1431-41.

45. Aubry J-F, Pauly K, Moonen C, Haar G, Ries M, Salomir R, Sokka S, Sekins KV, Shapira Y, Ye F, Huff-Simonin H, Eames M, Hananel A, Kassell N, Napoli A, Hwang JH, Wu F, Zhang L, Melzer A, Kim YS, Gedroyc WM. The road to clinical use of high-intensity focused ultrasound for liver cancer: technical and clinical consensus. J Ther Ultrasound. 2013: 1:13.

46. Wu F, Wang ZB, Chen WZ, Zhu H, Bai J, Zou JZ, Li KQ, Jin CB, Xie FL, Su HB. The road to clinical use of high-intensity focused ultrasound for liver cancer: technical and clinical consensus. Ann Surg Oncol. 2004; 11:1061-9.

47. Illing RO, Kennedy JE, Wu F, ter Haar GR, Protheroe AS, Friend PJ, Gleeson FV, Cranston DW, Phillips RR, Middleton MR. The safety and feasibility of extracorporeal high-intensity focused ultrasound (HIFU) for the treatment of liver and kidney tumours in a Western population. Br J Cancer. 2005; 93:890-5.

doi:10.1186/2050-5736-2-2

Cite this article as: Tyshlek et al:: Focused ultrasound development and clinical adoption: 2013 update on the growth of the field. Journal of Therapeutic Ultrasound 2014 2:2.

\section{Submit your next manuscript to BioMed Central and take full advantage of:}

- Convenient online submission

- Thorough peer review

- No space constraints or color figure charges

- Immediate publication on acceptance

- Inclusion in PubMed, CAS, Scopus and Google Scholar

- Research which is freely available for redistribution 